\title{
Evaluation and Assessment of Aflatoxin M1 in Milk and Milk Products in Yemen Using High-Performance Liquid Chromatography
}

\author{
Safwan Murshed (iD ${ }^{1,2}$ \\ ${ }^{1}$ Center of Biotechnology and Microbiology, University of Peshawar, Peshawar, Pakistan \\ ${ }^{2}$ Yemen Standardization, Metrology and Quality Control Organization, Sana'a, Yemen \\ Correspondence should be addressed to Safwan Murshed; safwan_1001@yahoo.com
}

Received 8 August 2020; Revised 7 September 2020; Accepted 10 September 2020; Published 23 September 2020

Academic Editor: Fabio Napolitano

Copyright (c) 2020 Safwan Murshed. This is an open access article distributed under the Creative Commons Attribution License, which permits unrestricted use, distribution, and reproduction in any medium, provided the original work is properly cited.

\begin{abstract}
Aflatoxin M1 is one of the major fungal contaminants found in dairy products around the globe. The objective of this study was to investigate the incidence and occurrence of aflatoxin M1 (AFM1) in samples of milk and milk products in Yemen. The tested dairy product samples were collected from different sources for aflatoxin M1 (AFM1) in Yemen. A total of 250 local and imported samples consisting of 38 liquid milk, 60 powder milk, 62 yogurt, and 90 cheese samples which are marketed throughout Yemen were tested by using high-performance liquid chromatography (HPLC) along with a fluorescence detector and immunoaffinity column purification for detection of AFM1. High levels of AFM1 were detected in preserved milk (77.24\%), ranging from $0.021 \mu \mathrm{g} / \mathrm{L}$ to $5.95 \mu \mathrm{g} / \mathrm{L}$. On the other hand, AFM1 was detected in $66.66 \%$ and $68.42 \%$ in powdered milk and liquid milk samples, respectively. Among dairy products, $87.09 \%$ of yogurt and $81.39 \%$ of cheese samples were found contaminated with AFM1. The AMF1 values were higher than the acceptable range for humans set by the European Union. So, we concluded that dairy products used in Yemen showed an AFM1 content beyond the acceptable range, and this is a major factor for causing health-related complications including cancer. In the present study, we reported for the first time the presence of mycotoxins especially AFM1 in dairy products used in Yemen.
\end{abstract}

\section{Introduction}

Aflatoxins $(\mathrm{AF})$ are highly carcinogenic toxins $[1-3]$ produced by different groups of fungi, especially Aspergillus flavus and Aspergillus parasiticus. These two strains A. flavus and $A$. parasiticus produce different types of aflatoxins including aflatoxin B1, B2, G1, and G2 [4]. A. parasiticus produces aflatoxin B1, B2, G1, and G2, while A. flavus merely produces aflatoxin $\mathrm{B} 1$ and $\mathrm{B} 2[5,6]$. Among these toxins, AFB1 is of great interest to livestock and dairy industry [7]. Toxigenic fungi are able to infect animal feed during plant growth, harvesting, and storage [8-11]. Aflatoxin M1 (AFM1), which is found in the milk of animals that have consumed feeds contaminated with AFB1, is the hydroxylated metabolite of aflatoxin B1 (AFB1) [12-14] and it is finally excreted in urine and milk and transmits in dairy products, i.e., fresh and processed milk, cheese, and yogurt.
AFM1 was the first aflatoxin detected in milk ( $\mathrm{M}$ denotes the source, e.g., milk) of cattle and other lactating mammals [15]. Numerous studies have reported the high carcinogenic potential of AFM1 [14]; therefore, the International Cancer Research Association (IARC) has classified AFB1 as a Group 1 carcinogen while aflatoxin M1 (AFM1) is classified as a Group 2B carcinogen [16].

In Yemen, cattle, sheep, and camels account for $20 \%$ of national agriculture GDP, and dairy production accounts for $28 \%$ of total animal GDP [17]. Despite multifaceted crises, the total milk production in Yemen increased by $71 \%$ from 299,008 tons in 2005 to 417,190 tons in 2011. Cow milk accounts for $71 \%$ (301,300 tons), goat milk $13 \%(53,455$ tons), sheep milk $10 \%$ (43,004 tons), and other sources $5 \%$. However, the annual milk yield recorded in 2011 was extremely low, i.e., $6,086 \mathrm{Hg} /$ animal (cow) as compared to developed countries [18]. Despite such a great increase by 
$71 \%$ in milk production, statistics from the Ministry of Agriculture and Irrigation, Yemen, reveals that the production of milk can only meet one-third of domestic demand. Thus, the country spends a huge amount of revenue on importing long life and powdered milk. Furthermore, more than $95 \%$ of processed dairy items are imported from neighboring and developed countries. There are main types of local dairy products such as fresh milk, laban (liquefied yogurt), and cheese from cattle while industrial dairy products (local industries and/or imported) include ultrahigh-temperature- (UHT-) treated milk, yogurt, laban (liquefied yogurt), cheese, ice cream, cream, and flavored milk.

The problem of food contaminated with AFM1 is a real concern and acts as a double-edged sword in zones of conflicts that are facing both humanitarian crises and food insecurities. The crisis in Yemen has put the lives of more than 24 million dwellers at risk [19] with approximately 15 million requiring humanitarian assistance, while about 11 million are facing malnutrition and food insecurity [20]. In the ongoing humanitarian crises in Yemen, one of the most vulnerable groups are children under five years [19-21]. Therefore, due to ongoing chronic food insecurities and malnutrition, alternative sources of feeding such as milk and milk products are sought for infants and children. However, the risk of contaminated milk and its products in markets is widespread, and the humanitarian crisis in conflict zones can exacerbate the food insecurities and health risks for the younger population $[12,22]$. So far, no data are available on the current status of mycotoxins, especially in dairy products.

In the current study, we aimed to investigate AFM1 in different types of dairy products marketed in Yemen. These findings will provide a baseline for a detailed assessment of risks associated with AFM1 and can help the country to develop policies for protecting its population from healthassociated risks caused by AFM1.

\section{Materials and Methods}

2.1. Sample Collection and Preparation. A total of 250 samples of commercial milk and milk products were purchased from different markets in Yemen. The samples consisted of 38 liquid milk (18 local samples and 20 imported samples), 60 powder milk, 62 yogurt (38 local samples and 24 imported samples), and 90 cheese (20 local samples and 70 imported samples) samples. All samples were refrigerated at $4^{\circ} \mathrm{C}$ until use. All samples were prepared for downstream analysis in aseptic conditions using sterilized ingredients.

2.1.1. Milk Sample Preparation. Liquid milk samples were placed at $35-37^{\circ} \mathrm{C}$ in a water bath. Samples were then manually shaken for $5 \mathrm{~min}$ to ensure sample homogeneity followed by centrifugation at $2000 \mathrm{rpm}$ for $15 \mathrm{~min}$ to separate and discard the fat layer using a spatula. The fatless samples were filtered using Whatman filter paper, and $50 \mathrm{~mL}$ of sample was transferred to the cleanup step.
For powder milk samples, $10 \mathrm{~g}$ of each sample was initially diluted in $50 \mathrm{~mL}$ water (preheated in the water bath to $50^{\circ} \mathrm{C}$ ) with continuous mixing using a glass rod until a homogeneous mixture was prepared. The beaker was placed in a water bath at $50^{\circ} \mathrm{C}$ to ensure complete dissolution. Samples were cooled down to $20^{\circ} \mathrm{C}$ to $25^{\circ} \mathrm{C}$ and transferred to a $100 \mathrm{~mL}$ volumetric flask. After the mixing process, the volume of each sample was adjusted to $100 \mathrm{~mL}$ with water. Filtration was done, and $50 \mathrm{~mL}$ of the prepared milk powder sample was transferred to the cleanup step. Artificially contaminated milk samples were prepared from aflatoxin-free milk and used as control.

2.1.2. Cheese and Yogurt Sample Preparation. Twenty-five grams of cheese and yogurt samples were added into a $250 \mathrm{~mL}$ volumetric flask or half-pint blender jar (in case samples contain butter melt sample) and $15 \mathrm{~g}$ of celite was added. $100 \mathrm{~mL}$ of methanol/water (80/20) (v/v) was added to each sample in a stopper flask or seal blender jar. Samples were mixed in a gyratory shaker for one hour or blended for 2 minutes at high speed. The solutions were filtered through filter paper (Whatman No. 4). In $10 \mathrm{~mL}$ of each extract, $40 \mathrm{~mL}$ of deionized water was added and transferred to the cleanup step.

2.2. Cleanup/Purification and HPLC Condition. The extraction of AFM1 from milk and milk products was performed according to the instructions enclosed with the test kit of immunoaffinity columns and the method described by Iqbal, Asi, and Jinap, 2013, with few modifications [23]. The samples are prepared as mentioned in Section 2.2. The extract was then filtered with Whatman No. 5 filter paper, and about $50 \mathrm{~mL}$ of the sample was passed through an AflaTest immunoaffinity column at a rate of $1-3 \mathrm{~mL} / \mathrm{minute}$ and washed with water $(10 \mathrm{ml})$ twice at the same flow rate. The bound AFM1 was eluted with HPLC grade acetonitrile (assay, 99.8\%) with $1.5-3.0 \mathrm{~mL}$ (i.e., $3 \times 0.5 \mathrm{ml}$ ) of solvent and collected in a vial. Finally, the residue was evaporated with nitrogen stream at $40^{\circ} \mathrm{C}$. The samples were placed in the dark place $(15 \mathrm{~min})$ at room temperature and the caps of the vials were tightly closed. Then, $200 \mu \mathrm{L}$ of acetonitrile was added to the vials. A $20 \mu \mathrm{L}$ portion of the solution was subjected to LC analysis. The HPLC system used in the current study was a Shimadzu Class vp, equipped with a multi- $\lambda$ fluorescence detector (FD) with an excitation wavelength of $365 \mathrm{~nm}$ and an emission wavelength of $435 \mathrm{~nm}$. The chromatographic column was C18 $5 \mathrm{~mm}(4.6 \times 250 \mathrm{~mm})$ (HS, Bellefonte, USA). The mobile phase (water: acetonitrile: methanol; $68: 24: 8, \mathrm{v} / \mathrm{v} / \mathrm{v}$ ) was run for $15 \mathrm{~min}$ at $30^{\circ} \mathrm{C}$ with a flow rate of $1 \mathrm{ml} / \mathrm{min}$. Calibration curve was prepared from either peak heights or peak areas by injecting $20 \mu \mathrm{L}$ of a series of standard solutions of AFM1 with concentrations of $0.05,0.1$, $0.5,1.0,2.5$, and $10 \mu \mathrm{g} / \mathrm{L}$ to ensure linear relationship. The retention time for AFM1 was 6.2-6.7 $\mathrm{min}$.

2.3. Recovery Check. The percentage of recovery (RC) determines the effectiveness of the analysis method that was spiked with known amounts of aflatoxins. 
Internationally, it is recommended that accepted RC be between 70 and $120 \%$. To prepare a spiked sample, an aflatoxin-free sample was taken and artificially contaminated samples (spike) were prepared by pipetting $5 \mu \mathrm{L}$ of $10 \mu \mathrm{g} / \mathrm{mL}$ standard to $100 \mathrm{~mL}$ of milk sample. Spiked milk was transferred to a beaker for mixing. $50 \mathrm{~mL}$ of the solution was placed into the immunoaffinity column carefully for analysis as described in the method mentioned previously. This sample solution was prepared which would test the method at levels that have been reported in commercial milk. The recovery of spiked samples was calculated for AFM1. The calculations were made on the basis of the following equation:

$$
W_{m}=W_{a} \times\left(\frac{V_{f}}{V_{i}}\right) \times\left(\frac{1}{V_{s}}\right),
$$

where $W_{m}=$ amount of AFM1 in the test sample in $\mu \mathrm{g} / \mathrm{L}$; $W_{a}=$ amount of AFM1corresponding to the area of AFM1 peak of the test extract (ng); $V_{f}=$ the final volume of redissolved eluate $(\mu \mathrm{L}) ; V_{i}=$ volume of injected eluate $(\mu \mathrm{L})$; and $V_{s}=$ volume of test portion (milk) passing through the column (mL).

2.4. Statistical Analysis. The data were analyzed and calculated for all statistical values, and the mean and standard deviation of all variables were calculated by using Microsoft Excel ${ }^{\circledR} 2013$ and SPSS application (Statistical Package for Social Sciences, version IBM 23). Descriptive statistics were performed to get frequencies and charts. For each sample of a given matrix, a series of three analyses are performed, and the coefficient SD represents the variability that can occur between the simultaneous analyses of the same samples.

2.5. Data Validation. Before analyzing the samples for AFM1, known AFM1 concentration was added to mycotoxinfree milk to determine recovery results. The result of the recovery experiment is shown in Table 1. Accuracy and validation of our work were assessed by spiking samples using three concentration levels, such as $0.05,0.1$, and $0.5 \mu \mathrm{g} / \mathrm{L}$. The recoveries were to some extent depending on spike levels but in any case better than $90 \%$ and precision is expressed as relative standard deviation percentage (RSD\%). The recovery at added level $0.5 \mathrm{ppb}$ was ranging from $102.94 \%$ to $108.31 \%$ and RSD was $<10 \%(n=3)$. Figure 1 shows the standard curve of aflatoxin M1 by the HPLC technique. The standard curve was linear $(y=649.56+12828.88 x, y=$ area and $x=$ amount $)$, and the standard concentrations were ranging from $0.05 \mu \mathrm{g} / \mathrm{L}$ to $10 \mu \mathrm{g} / \mathrm{L}$ AFM1 concentrations. The coefficient of determination $\left(R^{2}\right)$ was 0.99995 , and the limit of detection (LOD) was $0.002 \mu \mathrm{g} / \mathrm{L}$ for AFM1 in dairy products.

\section{Results and Discussion}

Amid security situation and ongoing conflict, Yemen, a developing country in the south of the Arabian Peninsula, is facing several health issues [24, 25]. Among these issues, cancer is a major public health issue and the underlying risk factors are not yet well understood in the south of Yemen. The most common cancers include breast cancer, leukemia, non-Hodgkin's lymphoma, brain cancer, and Hodgkin's disease [26]. Furthermore, the World Health Organization (WHO) estimates a total of 10,000 cancer deaths in Yemen in 2005 with 8000 of these occurring before the age of 70 [27]. Cancer deaths in Yemen accounted for about 5.6\% of all deaths in 2005 and are projected to reach $8.4 \%$ in 2030. AFM1 is one of the major factors associated with various types of cancers and health issues in humans and livestock [28]. AFM1-contaminated milk is one of the main sources of carcinogens; therefore, we investigated milk and dairy products for the contamination of AFM1 in different regions of Yemen during 2016-2017.

The AFM1 concentrations in milk (liquid and powder), yogurt, and cheese samples are summarized in Table 2 and illustrated in Figure 2. Overall, 250 samples of dairy products were tested for the prevalence of AFM1. Results described that out of 250 samples, 190 (76\%) were contaminated with AFM1. Positive samples were $26(68.42 \%)$ liquid milk samples, 40 (66.66\%) powder milk samples, 54 (87.09\%) yogurt samples, and $74(82.22 \%)$ cheese samples. A total of $130(52 \%)$ were contaminated at levels above the legal limits of the European Commission, i.e., $0.050 \mu \mathrm{g} / \mathrm{kg}$ for milk and 0.250 for cheese (Figure 3). On the other hand, the incidence of AFM1 contamination in local samples was $88.33 \%$, whereas $77.55 \%$ of imported samples were contaminated with AFM.

3.1. Milk Samples. A total of 98 samples ( 38 liquid milk and 60 powder milk samples) purchased from the markets of Yemen were analyzed for AFM1 by HPLC.

3.1.1. Liquid Milk Samples. Out of 38 liquid milk samples, 18 samples were local and 20 were imported samples. Of the total samples, 26 samples (68.42\%) were contaminated with AFM1 ranging from 0.021 to $0.418 \mu \mathrm{g} / \mathrm{L}$, and the average was $0.085 \mu \mathrm{g} / \mathrm{L}$. A total of $14(36.84 \%)$ samples had concentrations above the permissible limit $(0.05 \mu \mathrm{g} / \mathrm{L})$ set by EU regulation (Table 3 ). In our study, out of 18 local samples, 14 (77.77\%) were contaminated with AFM1 with an average of $0.047 \mu \mathrm{g} / \mathrm{L}$, ranging between 0.021 and $0.123 \mu \mathrm{g} / \mathrm{L}$ while 4 (22.22\%) of the local milk samples had concentrations above the permissible limit set by the EU regulation $(0.05 \mu \mathrm{g} / \mathrm{L})$. Among the total of 20 imported samples, 12 (60\%) samples were contaminated with an average of $0.113 \mu \mathrm{g} / \mathrm{L}$, ranging from 0.022 to $0.418 \mu \mathrm{g} / \mathrm{L}$. Among imported samples, 10 (50\%) samples had concentrations above the permissible limit set by the EU regulation $(0.05 \mu \mathrm{g} / \mathrm{L})$.

The high percentage of contaminated samples with AFM1 in the current study could be due to the use of contaminated batches of milk powder or contaminated raw milk for producing these samples. Many authors have observed a higher prevalence of contamination with AFM1 in liquid milk (89\%), of which $7.4 \%$ exceeds the threshold set by European regulations [29]. Similarly, in Iran, studies have evaluated the level of AFM1 in reconstituted milk and 
TABLE 1: Validation of detection protocol through recovery of known amount of mycotoxins in AFM1-free milk. AFM1-free samples were mixed with a known amount of AFM1 standard and analysed by HPLC.

\begin{tabular}{lccr}
\hline Spike sample & HPLC peak area & Recovery (\%) & $\begin{array}{c}\text { AFM1 con. in } \\
\text { milk (ppb) }\end{array}$ \\
\hline Sample 1 & 116395 & 108.31 & $0.541333 \pm 1.01$ \\
Sample 2 & 118984 & 110.73 & $0.553441 \pm 0.97$ \\
Sample 3 & 110651 & 102.94 & $0.514469 \pm 0.96$ \\
\hline
\end{tabular}

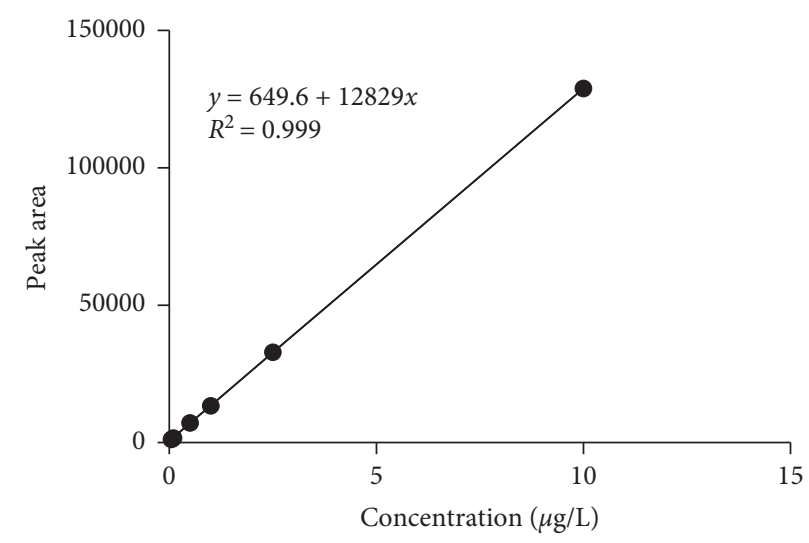

FIGURE 1: Standard curve of AFM1 contamination.

TABLE 2: AFM1 in different types of milk products determined by HPLC.

\begin{tabular}{lcccccccc}
\hline \multirow{2}{*}{ Milk products } & Number of samples & \multicolumn{2}{c}{$\begin{array}{c}\text { Contaminated } \\
\text { samples }\end{array}$} & \multicolumn{3}{c}{ Exceeding EC regulations $>0.05(\mu \mathrm{g} / \mathrm{L})$} \\
& & No. & $(\%)$ & No. & $(\%)$ & Range & Average & SD $^{\text {a }}$ \\
\hline Liquid milk & 38 & 26 & 68.42 & 14 & 36.84 & $0.065-0.418$ & 0.183 & 0.144 \\
Powder milk & 60 & 40 & 66.66 & 26 & 43.33 & $0.051-2.89$ & 0.635 & 0.952 \\
Yogurt & 62 & 54 & 87.09 & 52 & 83.87 & $0.053-.893$ & 0.399 & 0.310 \\
Cheese & 90 & 74 & 82.22 & 38 & 42.2 & $0.255-5.955$ & 1.198 & 0.114 \\
Total & 250 & 190 & 76 & 130 & 52 & $0.051-5.955$ & 0.604 & 0.380 \\
\hline
\end{tabular}

${ }^{\mathrm{a}} \mathrm{SD}=$ standard deviation.

reported the presence of AFM1 in milk. The contamination rate varies from $0.45 \mathrm{ng} / \mathrm{L}$ to $528.5 \mathrm{ng} / \mathrm{L}[30,31]$. In Syria, Ghanem and Orfi reported that pasteurized milk was contaminated ranging from 8 to $765 \mathrm{ng} / \mathrm{kg}$ [32]. On the other hand, in Lebanon, where pasteurized milk is reconstituted from powder milk imported from Arab or European countries, $68 \%$ of samples are contaminated with rates ranging from 3.27 to $84.4 \mathrm{ng} / \mathrm{L}$ [33]. Also, in Italy, the contamination of pasteurized milk with AFM1 was $1.6 \%$ of which $0.5 \%$ exceeds the standard recommended by the European Community [34].

3.1.2. Powder Milk Samples. The results of our study revealed that $66.66 \%$ of powdered milk samples were contaminated with AFM1. The levels of AFM1 ranged between 0.021 and $2.89 \mu \mathrm{g} / \mathrm{kg}$ and the average was $0.404 \mu \mathrm{g} / \mathrm{kg}$. Out of total samples, $26(43.33 \%)$ samples were above the permissible limit set by the EU (Table 3 ).

A similar study conducted in Korea revealed that $74 \%$ of powdered milk samples were contaminated with a mean concentration of $270.94 \mathrm{ng} / \mathrm{kg}$ [35]. In Lebanon, $35.7 \%$ of powder milk samples were contaminated with mean ranging from 9.18 to $16.5 \mathrm{ng} / \mathrm{L}$ and the average was $13.7 \mathrm{ng} / \mathrm{L}$ [33].

The variation in the mean of AFM1 contamination in powder milk may be attributed to differentiation in geographical regions, climatic factors, and season variability [36]. Furthermore, the differences in the origins of the feed of animals and different levels of contamination of raw milk may have affected the results. The previous studies indicated that the occurrence of AFM1 is higher in the cold season compared to the hot season because cattle are fed with a greater amount of compound feeds in cold seasons [37]. In industrialized countries, strict standards for imported products have been implemented. As a result of these measures, more contaminated products may be directed to markets where the legislation is either absent or are less restrictive [38]. All analyzed powder milk samples of our study were imported from other countries. Our finding was supported by the Joint FAO/WHO Expert Committee on Food Additives (JECFA) reports which state that the high levels of AFM1 in milk powder could be a result of complete removal of water, in order to concentrate [39]. 


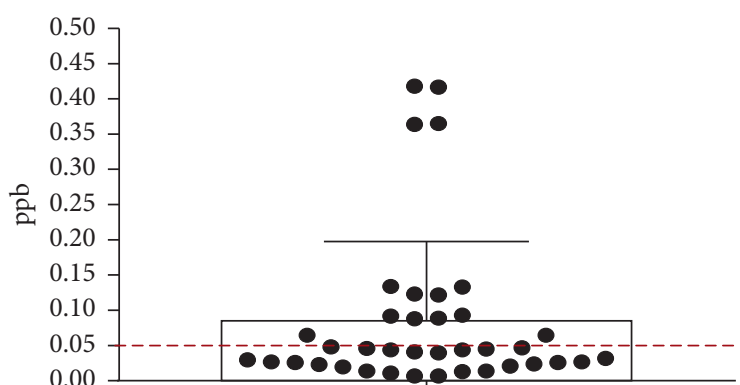

Fresh milk

(a)



(c)

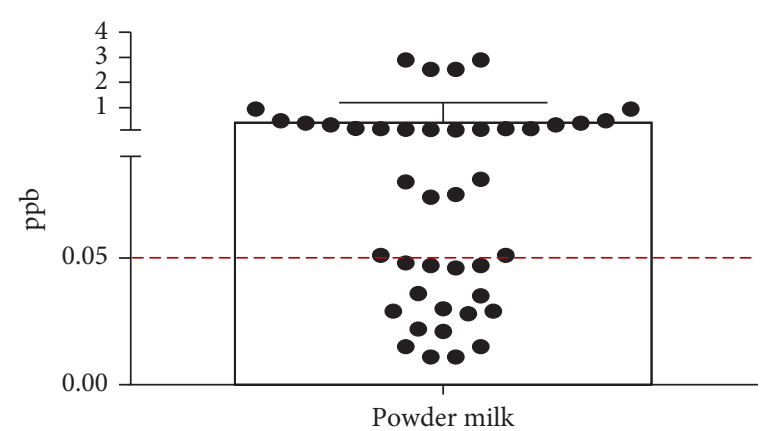

(b)

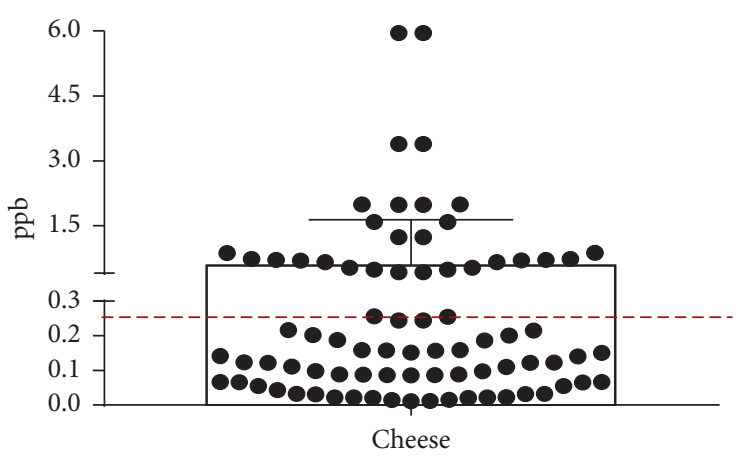

(d)

FIGURE 2: Distribution of aflatoxin M1 concentration in dairy product samples.



Figure 3: Aflatoxin M1 in different types of milk and milk products.

The high incidence of AFM1 in powder milk is an issue of great concern for public health especially in children as milk contains some major nutrients for the growth of children. So, we have suggested the continuous monitoring and surveillance on foodstuffs and feedstuffs to reduce consumer exposure to aflatoxins.
3.2. Yogurt Samples. A total of 62 yogurt samples, including 38 local and 24 imported yogurt samples, were analyzed. The results revealed that all local samples were contaminated with AFM1. The contamination of AFM1 ranged between 00.053 and $0.893 \mu \mathrm{g} / \mathrm{kg}$ with a mean of $0.515 \mu \mathrm{g} / \mathrm{kg}$. All local samples were contaminated with AFM1 above the permissible limit of EU regulation $(0.05 \mu \mathrm{g} / \mathrm{kg})$ while $66.66 \%$ of imported samples were contaminated with AFM1, out of which $58.33 \%$ exceeded the permissible limit. In general, the yogurt samples contaminated with AFM1 ranged from 0.021 to $0.893 \mu \mathrm{g} / \mathrm{kg}$ with a mean of $0.339 \mu \mathrm{g} / \mathrm{kg}$ (Table 4). A similar study was carried out in Italy. Out of 114 samples of yogurt, 91 (80\%) samples were positive for AFM1, ranging from $<1 \mathrm{ng} / \mathrm{L}$ to $496.5 \mathrm{ng} / \mathrm{L}$, with a mean level of $18.08 \mathrm{ng} / \mathrm{L}$ [40]. To put our results in perspective, it would be useful to compare them to similar reports elsewhere. The finding of our study was in agreement with those studies conducted in Iran by Barjesteh et al. [41], Behnamipour et al. [42] and Tabari et al. [43] in which all samples of yogurt were contaminated with AFM1 (100\%). In contrast to our finding, Ligia and Martins [44] in Portugal showed lower AFM1 contamination which was detected in 18 (18.8\%) of yogurt samples which ranged from 0.019 to $0.098 \mu \mathrm{g} / \mathrm{kg}$, and 78 samples (81.2\%) were not contaminated with AFM1. On the other hand, of the 48 natural yogurts tested, only 2 (4.2\%) were contaminated with 0.043 and $0.045 \mu \mathrm{g} / \mathrm{kg}$ of AFM1. Other studies conducted in Turkey by Lan et al., 2002, Akkaya et al. 2005, and Atasever et al., 2008 revealed contamination of yogurt with AFM1 was $12.5 \%, 62.83 \%$, and 
TABLE 3: AFM1 in liquid and powder milk samples through HPLC.

\begin{tabular}{|c|c|c|c|c|c|c|c|c|}
\hline \multicolumn{2}{|c|}{ Type of sample } & \multirow[t]{2}{*}{ No. of samples } & \multicolumn{4}{|c|}{ Contamination samples } & \multicolumn{2}{|c|}{$\begin{array}{c}\text { Exceeding EC regulations } \\
>0.05(\mu \mathrm{g} / \mathrm{L})\end{array}$} \\
\hline & & & No. (\%) & Range & Mean \pm SE & RSD & No. (\%) & Range \\
\hline \multirow{3}{*}{ Liquid milk } & Local & 18 & $14(77.77)$ & $0.021-0.123$ & $0.047 \pm 0.172$ & 0.098 & $4(22.22)$ & $0.087-0.123$ \\
\hline & Imported & 20 & $12(60)$ & $0.022-0.418$ & $0.113 \pm 0.19$ & 0.13 & $10(50)$ & $0.065-0.418$ \\
\hline & Total & 38 & $26(68.4)$ & $0.021-0.418$ & $0.085 \pm 0.182$ & 0.112 & $14(36.84)$ & $0.065-0.418$ \\
\hline Powder milk & Total samples & 60 & $40(66.6)$ & $0.021-2.89$ & $0.404 \pm 0.08$ & 0.681 & $26(43.33)$ & $0.051-2.89$ \\
\hline
\end{tabular}

TABLE 4: AFM1 in yogurt samples through HPLC.

\begin{tabular}{|c|c|c|c|c|c|c|c|}
\hline \multirow[t]{2}{*}{ Type of sample } & \multirow[t]{2}{*}{ No. of samples } & \multicolumn{4}{|c|}{ AFM1 contamination } & \multicolumn{2}{|c|}{$\begin{array}{c}\text { Exceeding EC regulations } \\
>0.05(\mu \mathrm{g} / \mathrm{kg})\end{array}$} \\
\hline & & No. (\%) & Range & Mean \pm SE & RSD & No. $(\%)$ & Range \\
\hline Local & 38 & $38(100)$ & $0.053-0.893$ & $0.515 \pm 0.07$ & 0.31 & $38(100)$ & $0.053-0.893$ \\
\hline Imported & 24 & $16(66.66)$ & $0.021-0.130$ & $0.134 \pm 0.09$ & 0.32 & $14(58.33)$ & $0.059-0130$ \\
\hline Total & 62 & $54(87.0)$ & $0.021-0.893$ & $0.339 \pm 0.09$ & 0.313 & $52(83.8)$ & $0.053-0.893$ \\
\hline
\end{tabular}

TABLe 5: AFM1 in cheese samples through HPLC.

\begin{tabular}{|c|c|c|c|c|c|c|c|}
\hline \multirow[t]{2}{*}{ Type of sample } & \multirow[t]{2}{*}{ No. of samples } & \multicolumn{4}{|c|}{ Contamination samples } & \multicolumn{2}{|c|}{$\begin{array}{c}\text { Exceeding EC regulations } \\
>0.250(\mu \mathrm{g} / \mathrm{Kg})\end{array}$} \\
\hline & & No. (\%) & Range & Mean \pm SE & RSD & No. $(\%)$ & Range \\
\hline Local & 20 & $16(72.97)$ & $0.022-3.38$ & $0.279 \pm 0.12$ & 1.087 & $10(50)$ & $0.323-3.387$ \\
\hline Imported & 70 & $58(82.85)$ & $0.022-5.95$ & $0.635 \pm 0.098$ & 1.011 & $28(40)$ & $0.255-5.955$ \\
\hline Total & 90 & $74(82.22)$ & $0.022-5.95$ & $0.567 \pm 0.11$ & 1.049 & $38(42.2)$ & $0.255-5.955$ \\
\hline
\end{tabular}

$80 \%$, respectively [45]. Several studies were carried out concerning the effect of yogurt manufacturing on AFM1 content, whereas some projects were reported with no influence on aflatoxin M1 concentration [46]. In contrast to our study which found a high frequency of AFM1 contamination in all yogurt samples, the previous studies discovered variable concentrations of aflatoxin M1 in yogurt compared to the milk. This variation of AFM1 content was evaluated due to the effect of fermentation. It was reported that aflatoxin M1 concentration in most yogurt samples showed a significant increase. This increase in aflatoxin M1 was ascribed to different factors such as the formation of organic acids, low $\mathrm{pH}$, other fermentation processes, or the existence of lactic acid bacteria [47]. This high percentage of contamination in yogurt may be attributed to manufacturers who usually used the imported dry milk for producing yogurt that was contaminated with AFM1 or used milk from animals grazing composite and stored fodder that may be contaminated with AFB1 [48]. AFM1 is resistant to thermal inactivation, pasteurization, autoclaving, and other different food processing procedures $[48,49]$. To reduce this toxin in dairy products, it is essential to keep feedstuffs free from contamination by AFB1. The concentration of AFB1 in feedstuffs can be reduced by good manufacturing practices (GMP) and good storage practices. It can also be reduced by chemical, physical, or biological treatment [50]. The current study reveals a high concentration of AFMI in all yogurt samples. Yogurt is the most popular dairy product consumed in Yemen, so AFM1 contamination in this product poses a high risk to public health.
3.3. Cheese Samples. The analysis of cheese samples showed that $82.22 \%$ of samples were contaminated with AFM1 (74 out of 90 ) including $72.97 \%$ local cheese samples and $82.85 \%$ imported cheese samples. The AFM1 contamination ranged from 0.022 to $5.955 \mu \mathrm{g} / \mathrm{kg}$ with an average of $0.567 \mu \mathrm{g} / \mathrm{kg}$. Among the total cheese samples, $42.2 \%$ of cheese samples were above the permissible limit of the EU regulation which ranged between 0.255 and $5.955 \mu \mathrm{g} / \mathrm{kg}$ (Table 5). The high concentration of AFM1 may be attributed to its environmental condition, bad storage condition, and high relative humidity [51]. Depending on the previous study conducted in 2016, there is a positive connection amid the AFM1 level, average rainfall, and humidity [52]. The values detected in this study were lower than those reported in a study conducted in Turkey which showed that $99 \%$ of cheese samples were contaminated with AFM1 [53]. Likewise, in Malaysia 2017, Nadira et al. reported that all samples of cheese were contaminated with AFM1 [54]. In agreement with our present study, in Turkey, $82.4 \%$ of white cheese samples were contaminated with AFM1 [55]. The variation of AFM1 presence in cheese samples is generally affected by different factors such as type of cheese studied, cheese-making procedures, geographical region, and cheese ripening conditions (e.g., humidity and temperature) [52]. The presence of aflatoxin M1 in cheese may be due to many reasons, i.e., AFM1 in cattle milk (raw milk) as a result of aflatoxin B1 from contaminated feedstuffs to milk, synthesis of aflatoxins (B1, B2, G1, and G2) by fungi A. flavus and A. parasiticus that grow on cheese samples, and cheese produced and manufactured from powdered or dried milk contaminated 
with AFM1 [56]. Since the contamination of feedstuffs with AFB1 plays a major role in the contamination of cheese and other dairy products, feedstuffs must be controlled and analyzed for AFB1 periodically. Also, the dairy product needs stringent quality control during processing and distribution, and this can be achieved by implementing good manufacturing practices (GMP).

Finally, we have found a high level of incidence of AFM1 in all samples of dairy products in Yemen. The outcome of the current study attracts great attention towards very significant health and food security risks for consumers in Yemen, especially to children.

Such observations prompted us to study dairy products for mycotoxins in Yemen and make an attempt to explain the high incidence of cancer in Yemen. Though our study is the first attempt, we believe that systematic research should be carried out to assess the mycotoxins in all consumed food and to study the risk associated with mycotoxins with support from public health authorities.

\section{Conclusion}

The current study revealed a high frequency of AFM1 contamination in milk and milk products. Therefore, all dairy products have to be controlled under the permissible limit. Since the AFM1 is considered as a significant risk for dairy products, stringent measures should be taken by health and food safety authorities through standard regulations and specifications such as inspection and surveillance on the dairy product and feedstuffs in regard to AFM1 and other aflatoxins. Moreover, imported dairy products should be screened at the entry point to the country. We further recommend that campaigns and strategies should be implemented for public awareness.

\section{Data Availability}

The data used to support the findings of this study are available from the corresponding author upon request.

\section{Conflicts of Interest}

All authors declare that they have no conflicts of interest.

\section{Acknowledgments}

This paper is dedicated to the fond memory of Dr. Nafees Bacha (1979-2019) my dear friend and $\mathrm{PhD}$ supervisor, who passed away during the course of this research.

\section{References}

[1] W. Anwar, H. Khaled, H. Amra, H. Elnezami, and C. Loffredo, "Changing pattern of hepatocellular carcinoma (HCC) and its risk factors in Egypt: possibilities for prevention," Mutation Research/Reviews in Mutation Research, vol. 659, no. 1-2, pp. 176-184, 2008.

[2] J. M. Cullen, B. H. Ruebner, L. S. Hsieh, D. M. Hyde, and D. P. Hsieh, "Carcinogenicity of dietary aflatoxin M1 in male fischer rats compared to aflatoxin B1," Cancer Research, vol. 47, no. 7, pp. 1913-1917, 1987.
[3] K.-Y. Peng and C.-Y. Chen, "Prevalence of aflatoxin M1 in milk and its potential liver cancer risk in Taiwan," Journal of Food Protection, vol. 72, no. 5, pp. 1025-1029, 2009.

[4] J. L. Richard, "Discovery of aflatoxins and significant historical features,” Toxin Reviews, vol. 27, no. 3-4, pp. 171-201, 2008.

[5] U. Gunsen and T. Yaroglu, "Aflatoxin in dog and horse feeds in Turkey," Veterinary and Human Toxicology, vol. 44, no. 2, pp. 113-114, 2002.

[6] J. I. Pitt, “Toxigenic fungi: which are important?" Medical Mycology, vol. 38, no. S1, pp. 17-22, 2000.

[7] E. E. Creppy, "Update of survey, regulation and toxic effects of mycotoxins in Europe," Toxicology Letters, vol. 127, no. 1-3, pp. 19-28, 2002.

[8] B. H. Armbrecht, "Aflatoxin residues in food and feed derived from plant and animal sources," in Residue Reviews, pp. 13-54, Springer, Berlin, Germany, 1972.

[9] S. K. Chattopadhyay, P. K. Taskar, O. Schwabe, Y. T. Das, and H. D. Brown, "Clinical and biochemical effects of aflatoxin in feed ration of chicks," Cancer Biochemistry Biophysics, vol. 8, no. 1, pp. 67-75, 1985.

[10] S. Dandoy, "Aflatoxin contamination of cottonseed," JAMA: The Journal of the American Medical Association, vol. 243, no. 8, pp. 731a-732, 1980.

[11] P. D. Andrade and E. D. Caldas, "Aflatoxins in cereals: worldwide occurrence and dietary risk assessment," World Mycotoxin Journal, vol. 8, no. 4, pp. 415-431, 2015.

[12] A. Alshannaq and J.-H. Yu, "Occurrence, toxicity, and analysis of major mycotoxins in food," International Journal of Environmental Research and Public Health, vol. 14, no. 6, p. 632, 2017.

[13] F. Galvano, V. Galofaro, A. de Angelis, M. Galvano, M. Bognanno, and G. Galvano, "Survey of the occurrence of aflatoxin M1 in dairy products marketed in Italy," Journal of Food Protection, vol. 61, no. 6, pp. 738-741, 1998.

[14] A. Prandini, G. Tansini, S. Sigolo, L. Filippi, M. Laporta, and G. Piva, "On the occurrence of aflatoxin M1 in milk and dairy products," Food and Chemical Toxicology, vol. 47, no. 5, pp. 984-991, 2009.

[15] R. E. Brackett and E. H. Marth, "Association of aflatoxin M1 with casein," Zeitschrift für Lebensmittel-Untersuchung und Forschung, vol. 174, no. 6, pp. 439-441, 1982.

[16] WHO \& IARC, Some Naturally Occurring Substances: Food Items and Constituents, Heterocyclic Aromatic Amines and Mycotoxins, vol. 56, pp. 489-521, WHO \& IARC, Lyon, France, 1993.

[17] A. Alabsi, "Country pasture/forage resource profiles," 2006, http:// www.fao.org/AG/AGP/agpc/doc/Counprof/Yemen/yemen.htm.

[18] FAOSTAT, Food and Agriculture Organization of the United Nations, FAO, Rome, Italy, 2018.

[19] S. Al-Sobaihi, K. Nakamura, and M. Kizuki, "Undernutrition among children under 5 years of age in Yemen: role of adequate childcare provided by adults under conditions of food insecurity," Journal of Rural Medicine, vol. 11, no. 2, pp. 47-57, 2016.

[20] J. Kandeh and L. Kumar, "Developing a relative ranking of social vulnerability of governorates of Yemen to humanitarian crisis," ISPRS International Journal of Geo-Information, vol. 4, no. 4, pp. 1913-1935, 2015.

[21] WFP, The State of Food Security and Nutrition in Yemen, Comprehensive Food Security Survey, Rome, Italy, 2012.

[22] T. A. Becker-Algeri, D. Castagnaro, K. Bortoli, C. Souza, D. A. Drunkler, and E. Badiale-Furlong, "Mycotoxins in bovine milk and dairy products: a review," Journal of Food Science, vol. 81, no. 3, 2016. 
[23] S. Z. Iqbal, M. R. Asi, and S. Jinap, "Variation of aflatoxin M1 contamination in milk and milk products collected during winter and summer seasons," Food Control, vol. 34, no. 2, pp. 714-718, 2013.

[24] M. A. A. Al-Ghazali, Y. A. Abdulmughni, M. A. K. AlMansoob et al., "Detection of aflatoxins B and M in serum of different types of cancer patients," World Journal of Medical Sciences, vol. 11, no. 4, pp. 570-577, 2014.

[25] O. Ecker, C. Breisinger, C. McCool et al., Assessing Food Security in Yemen: An Innovative Integrated, Cross-Sector, and Multilevel Approach, International Food Policy Research Institute (IFPRI), Washington, DC, USA, 2010.

[26] H. O. B. Saleem, A. A. Bawazir, M. Moore, and K. Abdulla, "Five years cancer incidence in Aden cancer registry, Yemen," Asian Pacific Journal of Cancer Prevention, vol. 11, pp. 507511, 2010.

[27] WHO, Estimates of the Global Burden of Foodborne Diseases: Foodborne Disease Burden Epidemiology Reference Group 2007-2015, WHO, Rome, Italy, 2015.

[28] M. S. Frehse, M. I. M. Martins, E. Y. S. Ono et al., "Aflatoxins ingestion and canine mammary tumors: there is an association?" Food and Chemical Toxicology, vol. 84, pp. 74-78, 2015.

[29] S. Redouane-Salah, D. P. Morgavi, R. Arhab, A. Messaï, and H. Boudra, "Presence of aflatoxin in raw, reconstituted, and powdered milk samples collected in Algeria," Environmental Monitoring and Assessment, vol. 187, no. 6, pp. 1-4, 2015.

[30] A. Behfar, Z. Nazari Khorasgani, Z. Alemzadeh, M. Goudarzi, R. Ebrahimi, and N. Tarhani, "Determination of aflatoxin M1 levels in produced pasteurized milk in Ahvaz city by using HPLC," Jundishapur Journal of Natural Pharmaceutical Products, vol. 7, no. 2, p. 80, 2012.

[31] A. M. Sani, H. Nikpooyan, and R. Moshiri, "Aflatoxin M1 contamination and antibiotic residue in milk in Khorasan province, Iran," Food and Chemical Toxicology, vol. 48, no. 89, pp. 2130-2132, 2010.

[32] I. Ghanem and M. Orfi, "Aflatoxin M1 in raw, pasteurized and powdered milk available in the Syrian market," Food Control, vol. 20, no. 6, pp. 603-605, 2009.

[33] E. Assem, A. Mohamad, and E. A. Oula, "A survey on the occurrence of aflatoxin $\mathrm{M} 1$ in raw and processed milk samples marketed in Lebanon," Food Control, vol. 22, no. 12, pp. 1856-1858, 2011.

[34] C. Nachtmann, S. Gallina, M. Rastelli, G. L. Ferro, and L. Decastelli, "Regional monitoring plan regarding the presence of aflatoxin M1 in pasteurized and UHT milk in Italy," Food Control, vol. 18, no. 6, pp. 623-629, 2007.

[35] D. Lee and K.-G. Lee, "Analysis of aflatoxin M1 and M2 in commercial dairy products using high-performance liquid chromatography with a fluorescence detector," Food Control, vol. 50, pp. 467-471, 2015.

[36] S. Hashimoto, M. D. Shogren, and Y. Pomeranz, "Cereal pentosans: their estimation and significance. I. Pentosans in wheat and milled wheat products," Cereal Chemistry, vol. 64, no. 1, pp. 30-34, 1987.

[37] F. Galvano, A. Pietri, T. Bertuzzi et al., Reduction of Carryover of Aflatoxin from Cow Feed to Milk by Addition of Activated Carbons, vol. 59, no. 5, pp. 551-554, Allen Press, Inc., Lawrence, KS, USA, 1996.

[38] I. Bakirci, "A study on the occurrence of aflatoxin M1 in milk and milk products produced in Van province of Turkey," Food Control, vol. 12, no. 1, pp. 47-51, 2001.

[39] N. Bilandžić, I. Varenina, B. Solomun Kolanović et al., "Occurrence of aflatoxin M1 in raw cow, goat and sheep milk during spring and autumn in Croatia during 2016," Toxin Reviews, vol. 36, no. 4, pp. 290-296, 2017.

[40] F. Galvano, V. Galofaro, A. Ritieni, M. Bognanno, A. De Angelis, and G. Galvano, "Survey of the occurrence of aflatoxin M1in dairy products marketed in Italy: second year of observation," Food Additives and Contaminants, vol. 18, no. 7, pp. 644-646, 2001.

[41] M. H. Barjesteh, I. Gholampour, and E. Noshfar, "Occurrence of aflatoxin M1 in pasteurized and local yogurt in mazandaran province (Northern of Iran) using ELISA," Global Veterinaria, vol. 4, no. 5, pp. 459-462, 2010.

[42] S. Behnamipour, Y. Arast, and M. Mohammadian, "Occurence of aflatoxin M1 in two dairy products by ELISA in central part of Iran,” Life Science Journal, vol. 9, no. 3, pp. 1831-1833, 2012.

[43] M. Tabari, K. Tabari, and O. Tabari, "Aflatoxin M1 determination in yoghurt produced in Guilan province of Iran using immunoaffinity column and high-performance liquid chromatography," Toxicology and Industrial Health, vol. 29, no. 1, pp. 72-76, 2013.

[44] M. Ligia and H. M. Martins, "Aflatoxin M1 in yoghurts in Portugal," International Journal of Food Microbiology, vol. 91, no. 3, pp. 315-317, 2004.

[45] M. Martins and H. M. Martins, "Aflatoxin M1 in yoghurts in Portugal," International Journal of Food Microbiology, vol. 91, no. 3, pp. 315-317, 2004.

[46] A. B. M. B. Tahoun, M. M. Ahmed, R. M. M. A. Elez, and S. S. AbdEllatif, "Aflatoxin M1 in milk and some dairy products: level, effect of manufacture and public health concerns," Zagazig Veterinary Journal, vol. 45, no. 2, 2017.

[47] Z. Sarlak, M. Rouhi, R. Mohammadi et al., "Probiotic biological strategies to decontaminate aflatoxin M1 in a traditional Iranian fermented milk drink (doogh), "Food Control, vol. 71, pp. 152-159, 2017.

[48] S. Umesha, H. M. G. Manukumar, B. Chandrasekhar et al., "Aflatoxins and food pathogens: impact of biologically active aflatoxins and their control strategies," Journal of the Science of Food and Agriculture, vol. 97, no. 6, pp. 1698-1707, 2017.

[49] L. B. Bullerman and A. Bianchini, "Stability of mycotoxins during food processing," International Journal of Food Microbiology, vol. 119, no. 1-2, pp. 140-146, 2007.

[50] A. Aiad and H. Sobhy, "Aflatoxin M1 levels in milk and some dairy products in Alexandria city," Assiut Veterinary Medical Journal, vol. 59, pp. 93-98, 2013.

[51] S. Khan, A. Ismail, Y. Y. Gong, S. Akhtar, and M. Hussain, "Concentration of aflatoxin M1 and selected heavy metals in mother milk samples from Pakistan," Food Control, vol. 91, pp. 344-348, 2018.

[52] F. B. Campagnollo, K. C. Ganev, A. M. Khaneghah et al., "The occurrence and effect of unit operations for dairy products processing on the fate of aflatoxin M1: a review," Food Control, vol. 68, pp. 310-329, 2016.

[53] K. K. Tekinşen and G. Uçar, "Aflatoxin M1 levels in butter and cream cheese consumed in Turkey," Food Control, vol. 19, no. 1, pp. 27-30, 2008.

[54] A. F. Nadira, J. Rosita, M. E. Norhaizan, and S. M. Redzwan, "Screening of aflatoxin M1 occurrence in selected milk and dairy products in Terengganu, Malaysia," Food Control, vol. 73, pp. 209-214, 2017.

[55] M. Ardic, Y. Karakaya, M. Atasever, and G. Adiguzel, "Aflatoxin M1 levels of Turkish white brined cheese," Food Control, vol. 20, no. 3, pp. 196-199, 2009.

[56] R. Darsanaki and M. Miri, "Aflatoxin M1 contamination in dairy products," Journal of Science and Today's World, vol. 2, 2013. 